\title{
A Comparative Research on Three Identification Methods of Scenic Resources of Tourism Based on GF-2 Image: A Case Study of Yesanpo National Park
}

\author{
Zhe Jia, Anchen Qin* \\ College of Landscape Architecture and Tourism, Hebei Agricultural University, Hebei Baoding, 071000 \\ China \\ *Corresponding author
}

\begin{abstract}
Based on the scientific identification and evaluation of scenic resources, the formulation of planning and management is of great significance to the sustainable development of tourism in national parks. This paper uses GF-2 high-resolution remote sensing images as the data source, and the Yesanpo National Park as the research area. It uses pixel-based MLC, NN, and SVM three classification methods to identify scenic resources, and adopts the system sampling method evaluation 3 methods to identify the classification accuracy of scenic resources, effectively improving the objectivity and accuracy of classification accuracy evaluation. The results show that the three classification methods used in GF-2 images meet the accuracy requirements of scenic resource identification, which is an effective method to identify scenic resources. Due to different geomorphic features, the erosion Zhanggu landform-Baili Xia scenic areas uses MLC classification, and granite fracture structure The canyon landform-Longmen Tianguan scenic areas uses NN classification, and the karst cave spring landform-Yugu Dong scenic areas uses SVM classification with the highest overall accuracy. The results show that the proposed method can be applied to the identification of large-scale, high-resolution scenic resources, and provide more refined data support for scenic resource analysis and sustainable development of local tourism.
\end{abstract}

Keywords: GF-2, scenic resource, pixel based classification, systematic sampling method, national park, Tourism

\section{Introduction}

Scenic resources are a symbol of the nature and culture of a region, and an important carrier and material basis for the development of national park. The digital identification and evaluation of scenic resources requires scientific and reliable technical support. With the development of remote sensing technology, especially high-resolution remote sensing technology, remote sensing images contain rich spatial information, texture features, and spectral information. They have the advantages of large-scale, multi-scale, dynamic, high-precision, and fast speed. The classification accuracy of remote sensing images is high. The level determines the accuracy of the resource classification information [1]. Early classification of remote sensing images is usually done through manual visual interpretation. This method is time-consuming, laborious and inefficient, with poor repeatability and a certain degree of subjectivity [2]. In order to solve the above problems, scholars gradually apply pixel-based classification methods such as Maximum Likelihood Classification (MLC), Minimum Distance Classification to remote sensing image classification [3]. For example, Li Hua et al. proposed a comprehensive improvement method based on MLC, which used sample filtering and normalization to improve the typicality of samples, and improved the MLC classifier. The improved overall accuracy increased by $9 \%$ [4].

With the continuous improvement of the spatial resolution of remote sensing images, many scholars have tried to introduce a variety of computer learning algorithms into the research and application of remote sensing image classification. A series of classification methods based on computer learning, such as Support Vector Machines (SVM) and Neural Networks (NN), have been proposed. Classification accuracy of remote sensing images. Among

ISSN: 0010-8189

www.converter-magazine.info 
Volume 2021, No. 4

them, the SVM theory was first proposed by the American mathematician Vladimir N. Vapnik, which is mainly used for the recognition of small samples of nonlinear high-dimensional patterns. In 2002, Huang et al. applied SVM to the classification of TM images, and believed that SVM is the best machine learning algorithm for small sample nonlinear high-dimensional pattern recognition, and can obtain higher classification accuracy [5]. Li Changjun et al. used the SVM method to identify the cultivated land in the remote sensing image of a prefecture-level city in Jiangsu Province, and the results showed that the overall effect of SVM on cultivated land classification was better, and the classification accuracy was greater than 90\% [6]. In 1995, Paola first used the NN classification method for remote sensing image classification [7]. Later, many domestic scholars also tried to improve NN and used it for remote sensing image classification and recognition. For example, Yang Yanqing used an improved Artificial Neural Network to identify land use information in remote sensing images of Hongtong County, Shanxi. And compared with the classification results of MLC, it is found that the improved ANN has higher classification accuracy and is more suitable for land use classification [8]. At the same time, in view of the shortcomings of ANN, such as dimensionality reduction and long classification time, Pan Yuan et al. proposed a NN classification based on rough set reduction and analyzed RapidEye images. The results showed that the classification accuracy using this method is better [9].

However, previous studies mostly focused on forestry [10-12], agriculture [13-15], ocean [16-20], geological resource classification [21], urban and rural planning [22-27] and other fields, based on Gaofen-2 (GF-2), there are few related researches on the identification and evaluation of scenic resources. The GF-2 satellite was launched in 2014, marking that the resolution of Chinese remote sensing satellites has entered the sub-meter era[28], including one $0.8 \mathrm{~m}$ panchromatic band (band $0.45-0.90 \mu \mathrm{m}$ ) and four $3.2 \mathrm{~m}$ multispectral bands [29].

In order to study the suitability of using different classification methods to identify different types of scenic resources for GF-2 images, this paper uses Yesanpo National Park as the research area, and uses pixel-based MLC, SVM, and NN for supervised classification. Identify the scenic resources of Forest, Grassland/Shrubland, Farmland, Architecture, Water, and use systematic sampling points to calculate confusion matrix and Kappa coefficient, evaluate classification accuracy, explore the methods suitable for identifying scenic resources in GF-2 images in MLC, NN, and SVM. Through this research, we will provide more accurate data support for the next scientific planning and management of scenic spots, provide reference for similar mountain scenic spots, and promote the research and application of GF-2 images in national park identification and evaluation, planning and sustainable development.

\section{Materials and Methods}

\subsection{Study area}

Yesanpo National Park is located in the northwest of Laishui County, Baoding City, at the eastern foot of the northern Taihang Mountain, the southern foot of the Yanshan Mountain, the Daqing River system in the Haihe River Basin, and the deep mountain area on the north and south banks of the Juma River. The total area is 505.48 $\mathrm{km}^{2}$. Scenic spots dominated by natural scenic resources are World Geopark and national-level scenic spots. Yesanpo is located on the "steps" of the North China Plain to the Shanxi Plateau. There are 3 types of typical geomorphic units: Baili Xia-erosion Zhanggu landform, Longmen Tianguan-granite fracture structure canyon landform, Yugu Dong-karst cave spring landform [30, 31]. The landform area of Baili Xia is $154.0 \mathrm{~km}^{2}$; the landform of Longmen Tianguan is $66.2 \mathrm{~km}^{2}$; the landform of Yugu Dong is $57.5 \mathrm{~km}^{2}$.

\subsection{Data preprocessing}

This paper uses GF-2 image data of Yesanpo National Park (collected on April 16, 2018), 2018 forest resource planning and design survey data and 2017-2020 field survey data. The remote sensing image data is preprocessed

ISSN: 0010-8189 
Volume 2021, No. 4 by atmospheric correction, orthorectification, fusion processing, geometric precision correction, etc. The results are shown in Figure 1.

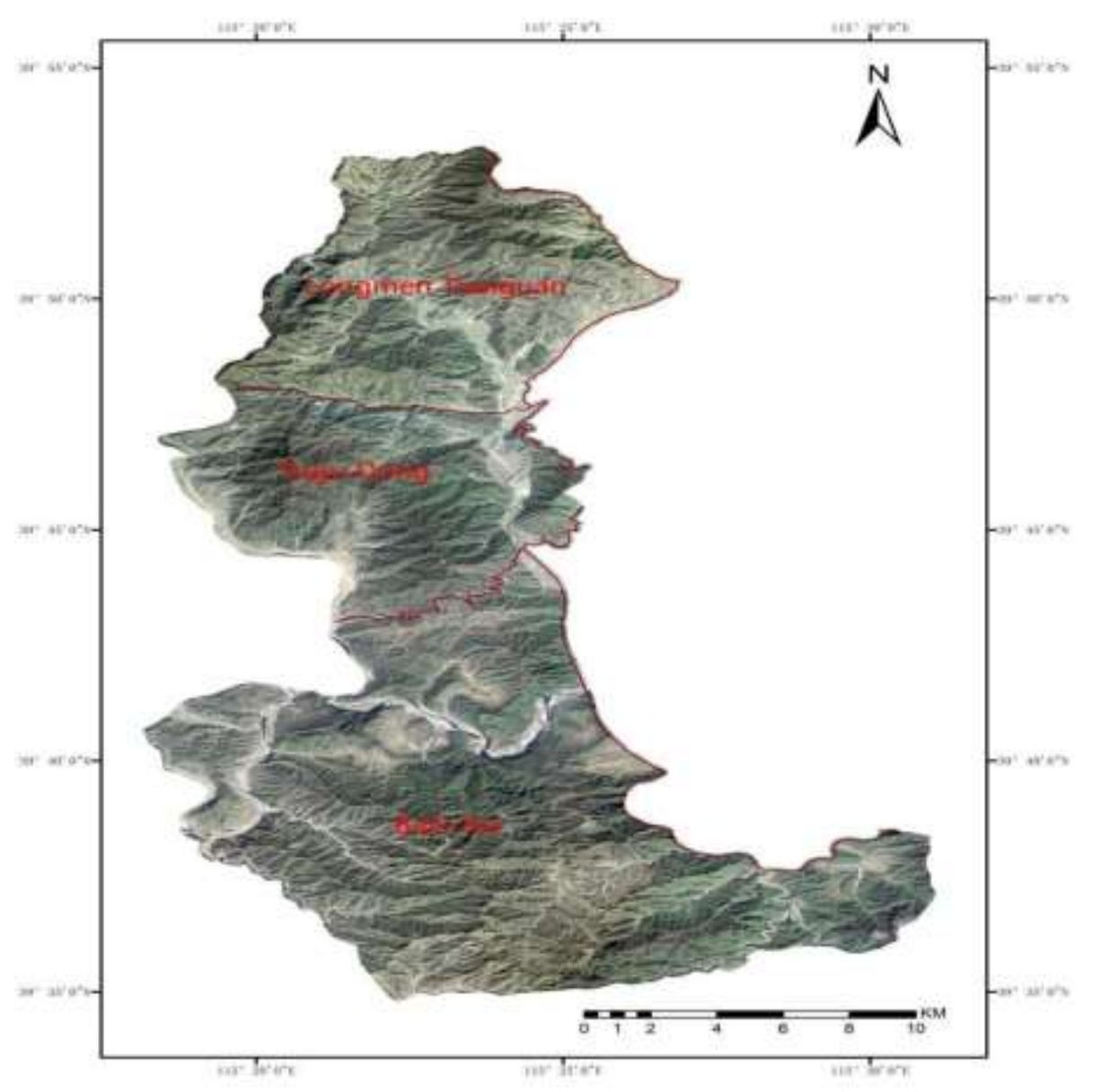

Fig.1: Remote sensing image of Yesanpo scenic and historic area

2.3 Pixel-based scenic resource recognition and accuracy evaluation

\subsubsection{Selection of classification method}

This paper uses pixel-based Maximum Likelihood Classification (MLC) [32], Neural Net (NN), and Support Vector Machine (SVM) three supervised classification methods to classify scenic resources in GF-2 images.

2.3.2 Evaluation method of classification accuracy of different geomorphic units

In this paper, a confusion matrix is used for accuracy evaluation. Its indicators include overall accuracy, mapping accuracy, user accuracy, and Kappa coefficient. The calculation formula is as follows.

Overall accuracy:

$$
p_{c}=\sum_{k=1}^{n} p_{k k} / p
$$

Prod. Acc:

ISSN: 0010-8189 


$$
p_{i j}=p_{i i} / p_{i+}
$$

User. Acc:

$$
p_{j i}=p_{i i} / p_{+j}
$$

Kappa Coefficient:

$$
K=\frac{p \times \sum_{k=1}^{n} p_{k k}-\sum_{i=1}^{n}\left(p_{+i} \times p_{i+}\right)}{p^{2}-\sum_{i=1}^{n}\left(p_{+i} \times p_{i+}\right)}
$$

In the formula, $n$ represents the number of categories, $P$ represents the total number of samples, and $P_{i j}$ is the component occupied by the $\mathrm{i}$-th type and the $\mathrm{j}$-th type of the reference image in the classification data type. $p_{i_{+}}=\sum_{j=1}^{n} p_{i j} \quad$ is the sum of the $\mathrm{i}$-th class obtained by classification. $\quad p_{+j}=\sum_{i=1}^{n} p_{i j} \quad$ is the sum of the jth category in the test data.

The calculation result of Kappa coefficient ranges from 0-1 [33], and the values are generally divided into five groups to indicate the level of consistency: between 0.0-0.2 is slight, and between 0.2-0.4 is fair, 0.4-0.6 is moderate, 0.6-0.8 is substantial, 0.8-1 is almost perfect [34].

In order to more scientifically and objectively verify the accuracy and difference between the three Pixel-Based classification methods, a systematic sampling method is used to extract the classification results corresponding to each classification method. Combining the vector data of field surveys in ArcGIS, the 2018 forest resources planning and design survey data were revised and merged for resource types, and a GIS database was established. Use the ArcGIS multi-value point extraction function to extract the actual scenic resource type corresponding to each sampling point from the corrected data as a true value test sample. In order to effectively cover all classifications in the national park, the sampling interval is set to $100 \mathrm{~m} \times 100 \mathrm{~m}$, of which hundreds of miles There are 15345 sample points in the Baili Xia, 6575 sample points in the Longmen Tianguan, and 5771 sample points in the Yugu Dong.

\section{Results}

3.1 GF-2 images of different geomorphic units Pixel-Based recognition results

3.1.1 GF-2 image recognition result of Baili Xia

The classification results of GF-2 images of Baili Xia using three Pixel-Based classification MLC, NN, and SVM are shown in Figure 2, Figure 3, and Figure 4.

ISSN: 0010-8189 
$\begin{array}{lllll}00.51 & 2 & 3 & 4 & 5\end{array}$
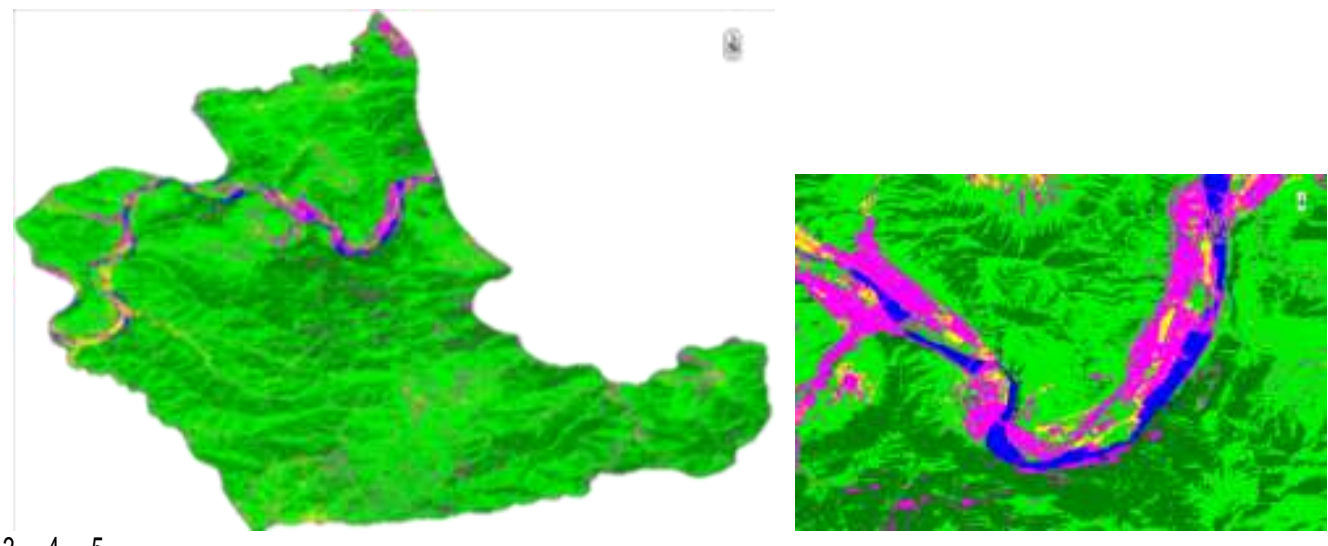

KM

$\square$ Forest

Grassland/Shrub

$\square$ Farmland

$\square$ Architecture

$\square$ Water

PS: The following legend is the same

Fig.2: MLC classified image of Baili Xia
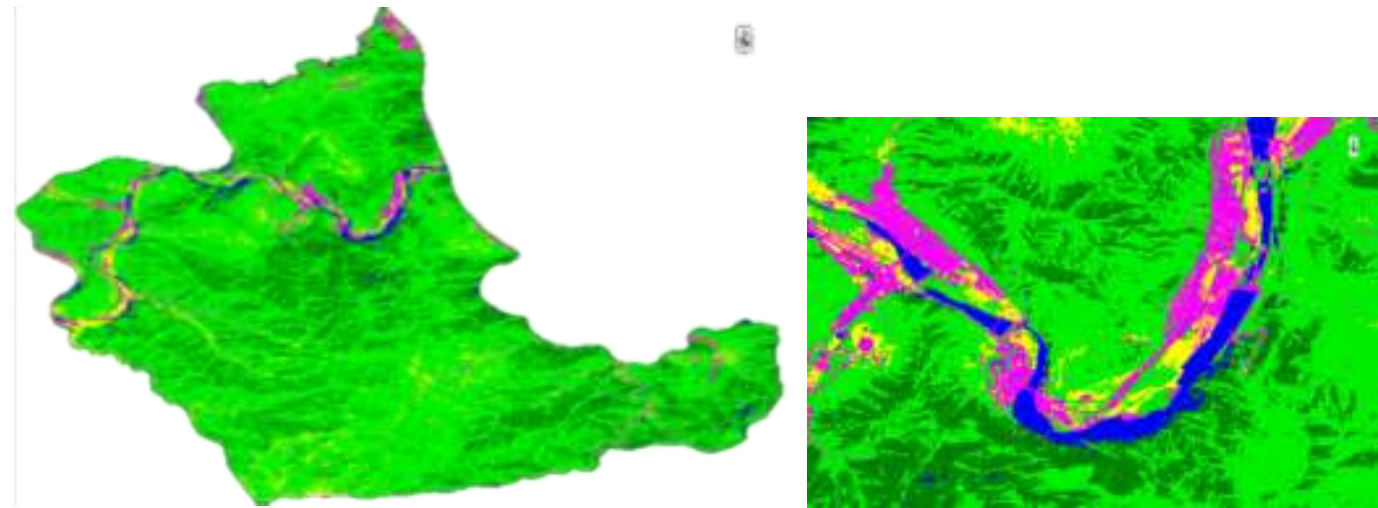

Fig.3: Neural Net classified image of Baili Xia
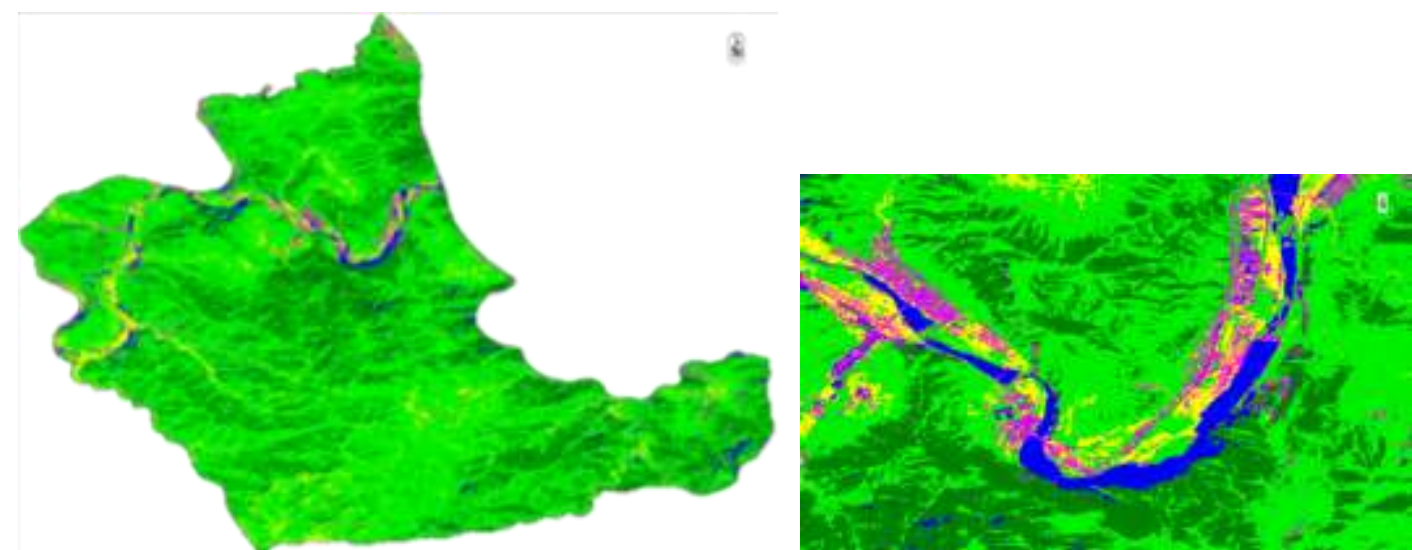

Fig.4: SVM classified image of Baili Xia

3.1.2 GF-2 image recognition results of Longmen Tianguan

The classification results of GF-2 images of Longmen Tianguan using three classification methods based on pixel MLC, NN, and SVM are shown in Figure 5, Figure 6, and Figure 7.

ISSN: 0010-8189

(C) CONVERTER 2020

www.converter-magazine.info 
CONVERTER MAGAZINE

Volume 2021, No. 4
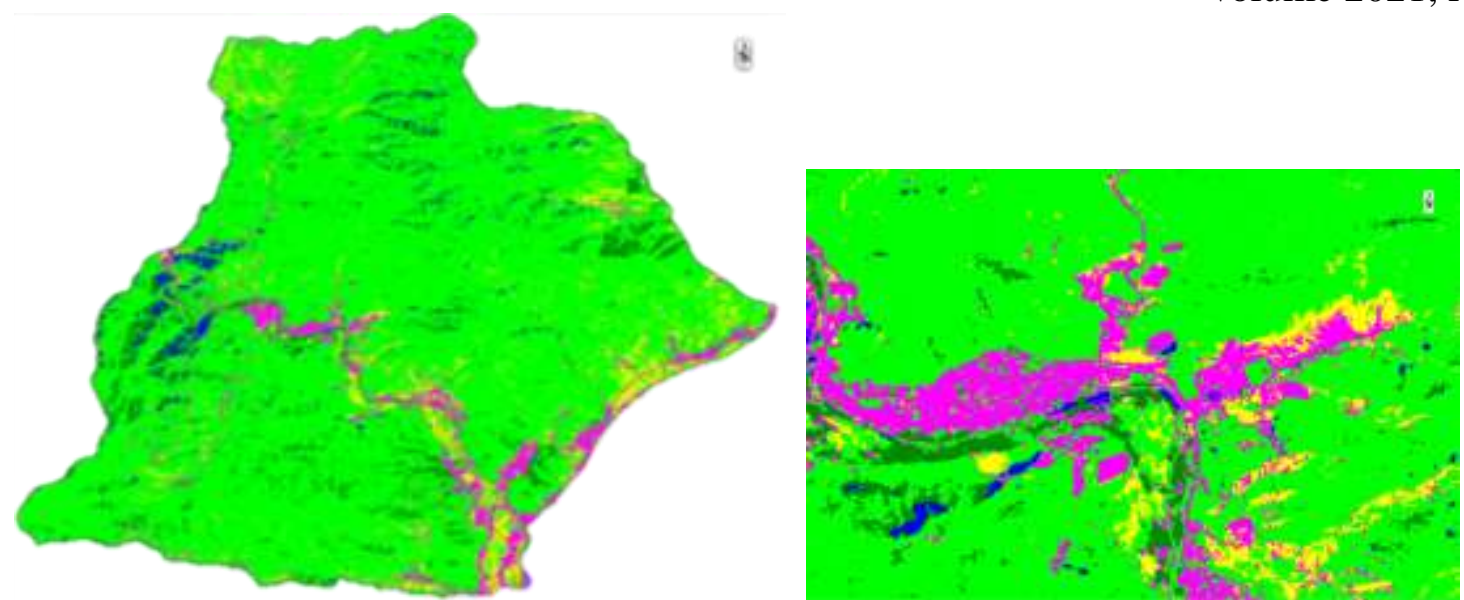

Fig.5: MLC classified image of Longmen Tianguan
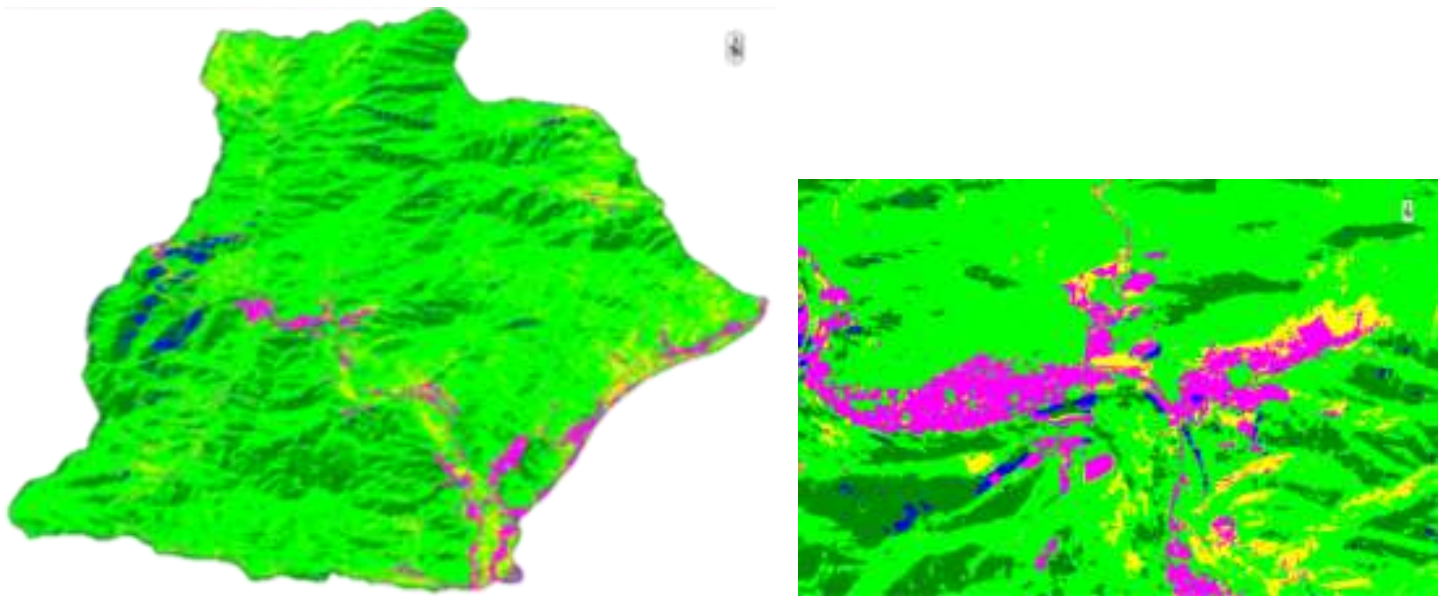

Fig.6: Neural Net classified image of Longmen Tianguan
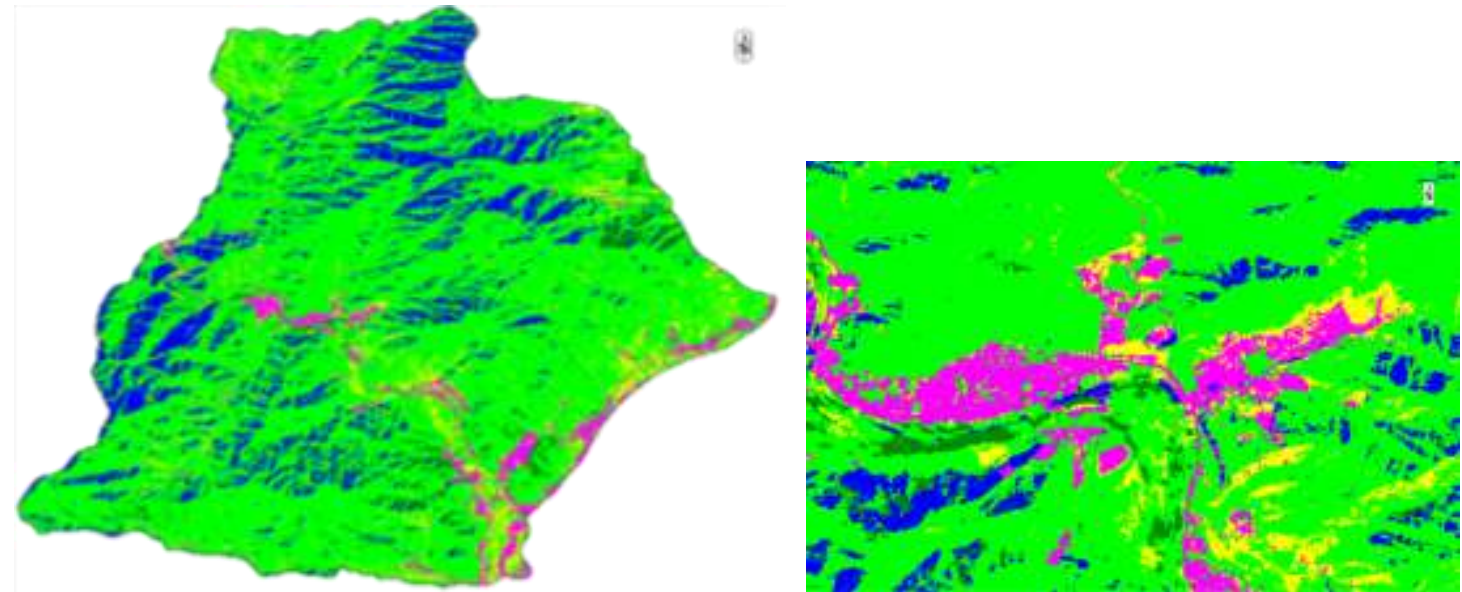

Fig.7: SVM classified image of Longmen Tianguan

3.1.3 GF-2 image recognition results of Yugu Dong

The classification results of GF-2 images of Yugu Dong using three classification methods based on pixel MLC, NN and SVM are shown in Figure 8, Figure 9, Figure 10.

ISSN: 0010-8189

(C) CONVERTER 2020

www.converter-magazine.info 
CONVERTER MAGAZINE

Volume 2021, No. 4
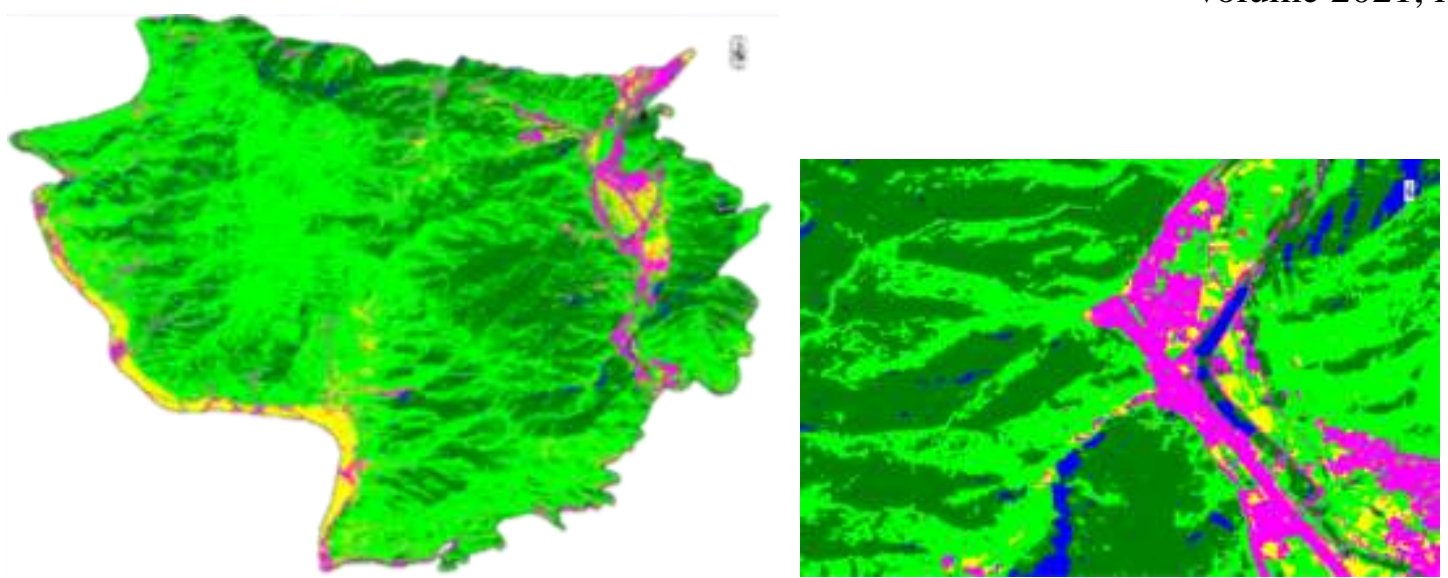

Fig.8: MLC classified image of Yugu Dong
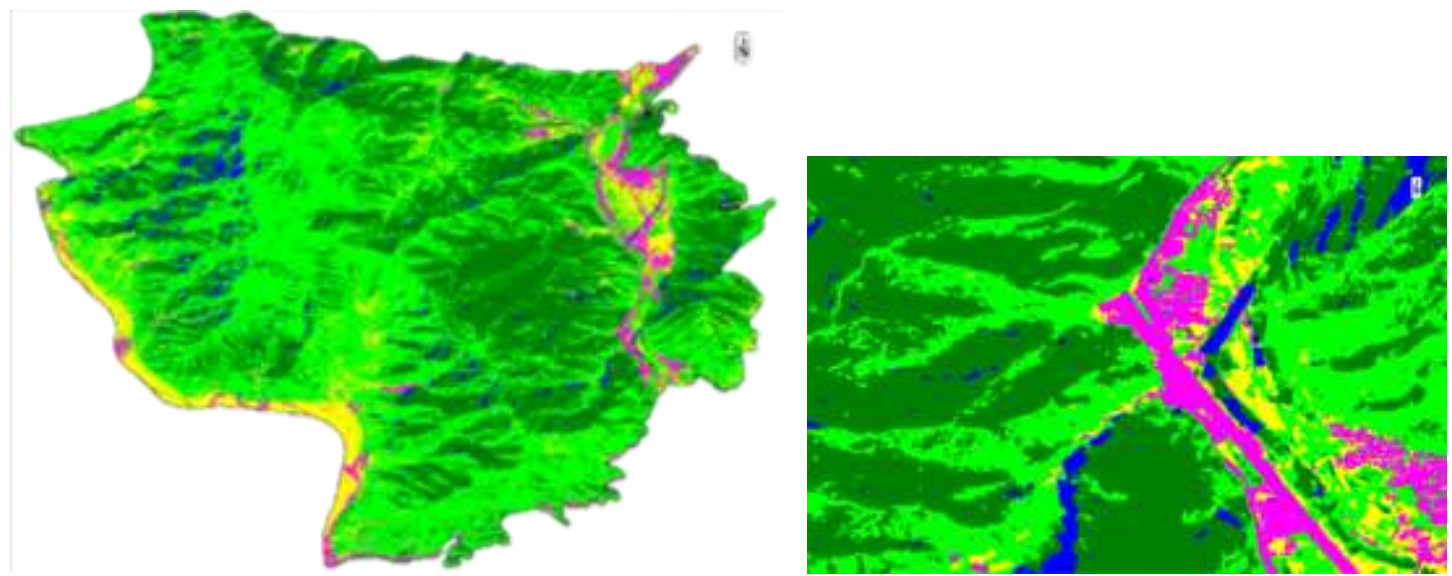

Fig.9: Neural Net classified image of Yugu Dong

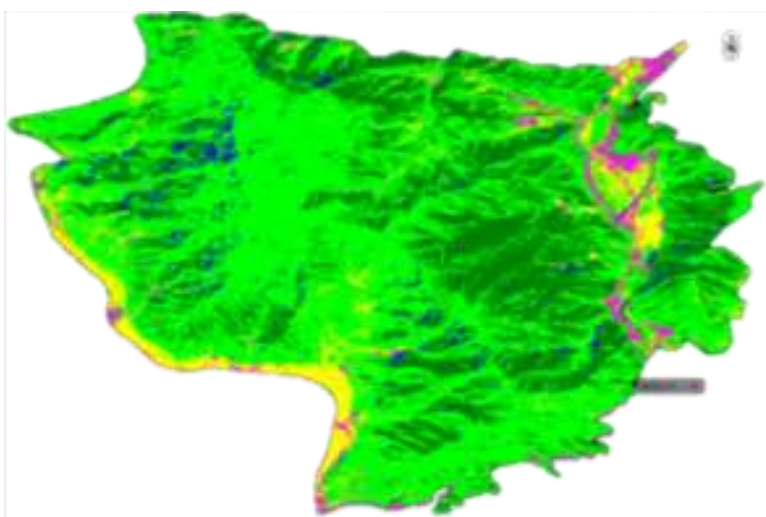

Fig.10: SVM classified image of Yugu Dong

3.2 Evaluation of the accuracy of scenic resource Pixel-Based classification

\subsubsection{Evaluation of Pixel-Based classification accuracy of Baili Xia}

Using three pixel-based classification methods to classify the five scenic resources in the landform unit, it is found that there are certain differences in the classification effect. The classification results are shown in Figure 2, Figure 3 , Figure 4, the calculated confusion matrix is shown in Table 1, and the classification accuracy is shown in Table 2 .

ISSN: 0010-8189

Www.converter-magazine.info 
CONVERTER MAGAZINE

Volume 2021, No. 4

Table.1 Confusion matrix table based on pixel classification of Baili Xia

\begin{tabular}{|c|c|c|c|c|c|c|c|c|}
\hline $\begin{array}{l}\text { Classificati } \\
\text { on } \\
\end{array}$ & Type & Forest & Grassland/Shrub & Farmland & $\begin{array}{c}\text { Architect } \\
\text { ure }\end{array}$ & $\begin{array}{c}\text { Wate } \\
\mathrm{r}\end{array}$ & \multicolumn{2}{|c|}{ Sample point } \\
\hline MLC & \multirow{3}{*}{ Forest } & 5477 & 1775 & 21 & 136 & 2 & 7410 & \\
\hline NN & & 4951 & 2376 & 36 & 25 & 23 & 7410 & \\
\hline SVM & & 5156 & 2146 & 37 & 21 & 52 & 7410 & \\
\hline MLC & Grassla & 599 & 5737 & 75 & 155 & 6 & 6571 & \\
\hline NN & nd/Shru & 358 & 5998 & 112 & 85 & 19 & 6571 & \\
\hline SVM & b & 423 & 5949 & 121 & 45 & 33 & 6571 & \\
\hline MLC & \multirow{3}{*}{$\begin{array}{c}\text { Farmlan } \\
\mathrm{d}\end{array}$} & 5 & 255 & 481 & 67 & 1 & 807 & \\
\hline NN & & 1 & 274 & 507 & 26 & 1 & 807 & \\
\hline SVM & & 2 & 289 & 509 & 6 & 2 & 807 & \\
\hline MLC & \multirow{3}{*}{$\begin{array}{c}\text { Architec } \\
\text { ture }\end{array}$} & 1 & 34 & 23 & 341 & 2 & 400 & \\
\hline $\mathrm{NN}$ & & 1 & 40 & 39 & 318 & 4 & 400 & \\
\hline SVM & & 1 & 78 & 57 & 259 & 5 & 400 & \\
\hline MLC & \multirow{3}{*}{ Water } & 3 & 9 & 2 & 24 & 120 & 157 & \\
\hline NN & & 1 & 15 & 2 & 14 & 126 & 157 & \\
\hline SVM & & 2 & 15 & 6 & 9 & 127 & 157 & \\
\hline MLC & \multirow{3}{*}{$\begin{array}{c}\text { Sample } \\
\text { point }\end{array}$} & 6084 & 7809 & 601 & 723 & 129 & Total samnle & \\
\hline NN & & 5311 & 8701 & 695 & 467 & 172 & Total sample & $\begin{array}{c}1534 \\
5\end{array}$ \\
\hline SVM & & 5584 & 8476 & 730 & 339 & 218 & points & 5 \\
\hline
\end{tabular}

Table.2 Accuracy evaluation of three kinds of remote sensing classification of Baili Xia

\begin{tabular}{|c|c|c|c|c|c|c|c|c|}
\hline Classification & Type & Forest & $\begin{array}{c}\text { Grassland/Shru } \\
\text { b }\end{array}$ & Farmland & Architecture & Water & Prod. Acc & Omission \\
\hline MLC & \multirow{3}{*}{ Forest } & 73.91 & 23.95 & 0.28 & 1.84 & 0.02 & 73.91 & 26.09 \\
\hline NN & & 66.82 & 32.06 & 0.49 & 0.34 & 0.30 & 66.82 & 33.18 \\
\hline SVM & & 69.57 & 28.95 & 0.50 & 0.28 & 0.70 & 69.57 & 30.43 \\
\hline MLC & Grassla & 9.12 & 87.31 & 1.13 & 2.35 & 0.09 & 87.31 & 12.69 \\
\hline NN & nd/Shru & 5.45 & 91.28 & 1.70 & 1.29 & 0.29 & 91.28 & 8.72 \\
\hline SVM & b & 6.44 & 90.53 & 1.84 & 0.68 & 0.50 & 90.53 & 9.47 \\
\hline MLC & \multirow{3}{*}{$\begin{array}{l}\text { Farmla } \\
\text { nd }\end{array}$} & 0.56 & 31.54 & 59.54 & 8.30 & 0.06 & 59.54 & 40.46 \\
\hline NN & & 0.06 & 33.89 & 62.76 & 3.16 & 0.12 & 62.76 & 37.24 \\
\hline SVM & & 0.25 & 35.81 & 63.07 & 0.68 & 0.19 & 63.07 & 36.93 \\
\hline MLC & \multirow{3}{*}{$\begin{array}{l}\text { Archite } \\
\text { cture }\end{array}$} & 0.13 & 8.50 & 5.75 & 85.25 & 0.38 & 85.25 & 14.75 \\
\hline $\mathrm{NN}$ & & 0.13 & 9.88 & 9.63 & 79.50 & 0.88 & 79.50 & 20.50 \\
\hline SVM & & 0.25 & 19.50 & 14.25 & 64.75 & 1.25 & 64.75 & 35.25 \\
\hline MLC & \multirow{3}{*}{ Water } & 1.91 & 5.41 & 1.27 & 15.29 & 76.11 & 76.11 & 23.89 \\
\hline $\mathrm{NN}$ & & 0.64 & 9.24 & 1.27 & 8.92 & 79.94 & 79.94 & 20.06 \\
\hline SVM & & 1.27 & 9.24 & 3.50 & 5.41 & 80.57 & 80.57 & 19.43 \\
\hline MLC & \multirow{3}{*}{$\begin{array}{l}\text { Prod. } \\
\text { Acc }\end{array}$} & 90.02 & 73.47 & 79.95 & 47.20 & 92.64 & & 79.21 \\
\hline $\mathrm{NN}$ & & 93.22 & 68.93 & 72.93 & 68.09 & 73.18 & $\mathrm{OA}$ & 77.54 \\
\hline SVM & & 92.33 & 70.19 & 69.77 & 76.51 & 58.16 & & 78.19 \\
\hline MLC & \multirow{3}{*}{$\begin{array}{l}\text { Commi } \\
\text { ssion }\end{array}$} & 9.98 & 26.53 & 20.05 & 52.80 & 7.36 & & 0.65 \\
\hline NN & & 6.78 & 31.07 & 27.07 & 31.91 & 26.82 & Kappa & 0.62 \\
\hline SVM & & 7.67 & 29.81 & 30.23 & 23.49 & 41.84 & & 0.63 \\
\hline
\end{tabular}

Note: Except for Kappa coefficient, all values in the table are percentages (\%)

The analysis of Table 2 shows that Baili Xia uses three pixel-based classification methods to classify scenic resources with different accuracy. The overall accuracy of MLC classification is $79.21 \%$; the Kappa coefficient is 0.65, which is between 0.6-0.8. It belongs to substantial. The classification results of 5 kinds of scenic resources are as follows:

(1) Forest: It is mainly classified as grass/shrubland and architecture. The main reason is that some forest is

ISSN: 0010-8189

(C) CONVERTER 2020

www.converter-magazine.info 

secondary forest, which is easy to be confused with grassland/shrubland. The final classification of forest is smaller than the actual area.

(2) Grassland/shrubland: Mainly misclassified into forest, architecture and farmland. The main reason is the mixed distribution of some grassland/shrubland and forest, which is easy to be confused and misclassified. In the end, the classified area of grassland/shrubland is larger than actual.

(3) Farmland: It is mainly classified as grass/shrubland and architecture. The main reason is that the remote sensing data source was obtained in April 2018. In spring, grassland/shrubland is easily classified as farmland. In the end, the classified area of farmland is smaller than the actual area.

(4) Architecture: It is mainly divided into grass/shrubland and farmland. The main reason is that there are many grass/shrubland and farmland around the architecture, which can be easily confused. The final use of MLC, NN architecture classification area is larger than actual.

(5) Water: Mainly divided into architecture, grassland/shrubland, forest, and farmland. The main reason is that the surrounding architecture, grassland/shrubland, forest, and farmland are easily confused, and some shadows in mountain areas are also wrongly divided into Water. In the end, the area of water classification using NN and SVM is larger than the actual area.

3.2.2 Evaluation of pixel-based classification accuracy of Longmen Tianguan

Using three pixel-based classification methods to classify the five scenic resources in the landform unit, it is found that there are certain differences in the classification effect. The classification results are shown in Figure 5, Figure 6, and Figure 7, the confusion matrix is shown in Table 3, and the classification accuracy is shown in Table 4.

Table.3 Confusion matrix table based on pixel classification of Longmen Tianguan

\begin{tabular}{cccccccc}
\hline $\begin{array}{c}\text { Classificati } \\
\text { on }\end{array}$ & \multirow{2}{*}{ Type } & $\begin{array}{c}\text { Fore } \\
\text { st }\end{array}$ & $\begin{array}{c}\text { Grassland/Shr } \\
\text { ub }\end{array}$ & $\begin{array}{c}\text { Farmlan } \\
\text { d }\end{array}$ & $\begin{array}{c}\text { Architectu } \\
\text { re }\end{array}$ & $\begin{array}{c}\text { Wate } \\
\text { r }\end{array}$ & Sample point \\
\hline MLC & & 1452 & 1084 & 43 & 27 & 34 & 2639 \\
NN & Forest & 1714 & 827 & 52 & 19 & 29 & 2639 \\
SVM & & 1388 & 888 & 38 & 13 & 313 & 2639 \\
MLC & Grassland/Shr & 52 & 3195 & 83 & 29 & 22 & 3380 \\
NN & ub & 204 & 3050 & 87 & 19 & 21 & 3380 \\
SVM & & 27 & 3144 & 66 & 15 & 130 & 3380 \\
MLC & & 2 & 81 & 213 & 19 & 0 & 314 \\
NN & Farmland & 2 & 86 & 213 & 14 & 0 & 314 \\
SVM & & 1 & 96 & 204 & 13 & 1 & 314 \\
MLC & & 2 & 22 & 10 & 196 & 1 & 230 \\
NN & Architecture & 2 & 27 & 12 & 190 & 1 & 230 \\
SVM & & 2 & 27 & 15 & 186 & 2 & 7 \\
MLC & & 1 & 3 & 0 & 2 & 7 & 12 \\
NN & Water & 2 & 3 & 0 & 1 & 7 & 12 \\
SVM & & 1 & 3 & 0 & 1 & 8 & 12 \\
MLC & & 1509 & 4385 & 348 & 271 & 63 & Total sample \\
NN & Sample point & 1922 & 3992 & 364 & 241 & 57 & points \\
SVM & & 1418 & 4156 & 322 & 227 & 453 & 5 \\
\hline
\end{tabular}

Table.4 Accuracy evaluation of three kinds of remote sensing classification of Longmen Tianguan

\begin{tabular}{ccccccccc}
\hline $\begin{array}{c}\text { Classificatio } \\
\mathrm{n}\end{array}$ & \multirow{2}{*}{ Type } & Forest & $\begin{array}{c}\text { Grassland/Shru } \\
\mathrm{b}\end{array}$ & Farmland & Architecture & Water & Prod.Acc & Omission \\
\hline MLC & \multirow{2}{*}{ Forest } & 55.02 & 41.06 & 1.63 & 1.00 & 1.29 & 55.02 & 44.98 \\
NN & 64.93 & 31.32 & 1.97 & 0.70 & 1.08 & 64.93 & 35.07 \\
\hline
\end{tabular}

ISSN: 0010-8189 
CONVERTER MAGAZINE

\begin{tabular}{ccccccccc}
\multicolumn{1}{l}{} & & \multicolumn{1}{c}{ Volume 2021, No. 4 } \\
\hline SVM & & 52.60 & 33.63 & 1.44 & 0.47 & 11.86 & 52.60 & 47.40 \\
MLC & Grassla & 1.54 & 94.53 & 2.46 & 0.84 & 0.64 & 94.53 & 5.47 \\
NN & nd/Shru & 6.02 & 90.22 & 2.57 & 0.56 & 0.62 & 90.22 & 9.78 \\
SVM & b & 0.78 & 93.00 & 1.94 & 0.44 & 3.83 & 93.00 & 7.00 \\
MLC & Farmla & 0.64 & 25.80 & 67.68 & 5.89 & 0.00 & 67.68 & 32.32 \\
NN & nd & 0.64 & 27.39 & 67.68 & 4.30 & 0.00 & 67.68 & 32.32 \\
SVM & & 0.32 & 30.41 & 64.97 & 3.98 & 0.32 & 64.97 & 35.03 \\
MLC & Archite & 0.65 & 9.57 & 4.13 & 85.22 & 0.43 & 85.22 & 14.78 \\
NN & cture & 0.65 & 11.52 & 5.22 & 82.39 & 0.22 & 82.39 & 17.61 \\
SVM & & 0.65 & 11.52 & 6.30 & 80.87 & 0.65 & 80.87 & 19.13 \\
MLC & & 8.33 & 25.00 & 0.00 & 12.50 & 54.17 & 54.17 & 45.83 \\
NN & Water & 12.50 & 25.00 & 0.00 & 4.17 & 58.33 & 58.33 & 41.67 \\
SVM & & 8.33 & 25.00 & 0.00 & 4.17 & 62.50 & 62.50 & 37.50 \\
MLC & User.Ac & 96.25 & 72.87 & 61.06 & 72.32 & 10.32 & & 76.99 \\
NN & c & 97.15 & 76.40 & 58.46 & 78.63 & 12.28 & OA & 78.66 \\
SVM & & 75.64 & 63.35 & 82.12 & 1.66 & & 74.97 \\
MLC & Commi & 3.75 & 27.13 & 38.94 & 27.68 & 89.68 & & 0.59 \\
NN & ssion & 10.85 & 23.60 & 41.54 & 21.37 & 87.72 & Kappa & 0.62 \\
SVM & & 2.12 & 24.36 & 36.65 & 17.88 & 98.34 & & 0.57 \\
\hline
\end{tabular}

Note: Except for Kappa coefficient, all values in the table are percentages (\%)

The analysis of Table 4 shows that Longmen Tianguan uses three pixel-based classification methods to classify scenic resources with different accuracy. Among them, the overall accuracy of NN classification is the highest, $78.66 \%$; the Kappa coefficient is 0.62 , which is between 0.6-0.8. , Belongs to substantial. The classification results of 5 kinds of scenic resources are as follows:

(1) Forest: Mainly misclassified into grassland/shrubland, farmland, architecture and water. The main reason is that some forest is easily confused with grassland/shrubland. The final classification of forest is smaller than the actual area.

(2) Grassland/shrubland: Mainly misclassified into farmland, forest and architecture. The main reason is that grassland/shrubland is distributed in some farmland, which is easy to be misclassified from crops. In the end, the classified area of grassland/shrubland is larger than actual.

(3) Farmland: It is mainly classified as grass/shrubland and architecture. The main reason is that the remote sensing data source was obtained in April 2018. There are crops in the spring farmland, which is similar in nature to grassland/shrubland and is easy to be misclassified. . In the end, the classified area of farmland is larger than the actual area.

(4) Architecture: It is mainly classified as grass/shrubland and farmland. The main reason is that there are many scattered grass/shrubland and farmland around the architecture, which is easy to be misclassified. The final use of MLC, NN architecture classification area is larger than actual.

(5) Water: It is mainly classified as architecture, forest, grassland/shrub. The main reason is that architecture, forest, grassland/shrubland around the water are easily confused, and mountain shadows are also incorrectly classified as water. In the end, the classified area of water is larger than the actual area.

\subsubsection{Evaluation of Pixel-Based classification accuracy Yugu Dong}

Using three pixel-based classification methods to classify the five scenic resources in the landform unit, it is found that there are certain differences in the classification effect. The classification results are shown in Figure 8, Figure 9, Figure 10, the confusion matrix is shown in Table 5, and the classification accuracy is shown in Table 6.

ISSN: 0010-8189 
CONVERTER MAGAZINE

Volume 2021, No. 4

Table.5 Confusion matrix table based on pixel classification of Yugu Dong

\begin{tabular}{|c|c|c|c|c|c|c|c|}
\hline Classification & Type & Forest & $\begin{array}{c}\text { Grassland/Shru } \\
\text { b }\end{array}$ & Farmland & Architecture & Water & Sample point \\
\hline MLC & \multirow{3}{*}{ Forest } & 1619 & 606 & 17 & 24 & 16 & 2280 \\
\hline NN & & 1689 & 507 & 25 & 8 & 53 & 2280 \\
\hline SVM & & 1581 & 635 & 19 & 7 & 38 & 2280 \\
\hline MLC & \multirow{3}{*}{$\begin{array}{c}\text { Grassland/ } \\
\text { Shrub }\end{array}$} & 408 & 2429 & 35 & 31 & 13 & 2915 \\
\hline $\mathrm{NN}$ & & 459 & 2360 & 52 & 13 & 32 & 2915 \\
\hline SVM & & 363 & 2472 & 44 & 12 & 25 & 2915 \\
\hline MLC & \multirow{3}{*}{ Farmland } & 5 & 53 & 289 & 28 & 0 & 375 \\
\hline $\mathrm{NN}$ & & 9 & 52 & 295 & 20 & 1 & 375 \\
\hline SVM & & 5 & 58 & 300 & 12 & 1 & 375 \\
\hline MLC & \multirow{3}{*}{$\begin{array}{c}\text { Architectu } \\
\text { re }\end{array}$} & 7 & 16 & 10 & 142 & 0 & 174 \\
\hline NN & & 7 & 20 & 14 & 133 & 1 & 174 \\
\hline SVM & & 6 & 24 & 16 & 129 & 0 & 174 \\
\hline MLC & \multirow{3}{*}{ Water } & 2 & 1 & 2 & 9 & 15 & 27 \\
\hline NN & & 2 & 3 & 4 & 4 & 15 & 27 \\
\hline SVM & & 2 & 3 & 4 & 4 & 15 & 27 \\
\hline MLC & \multirow{3}{*}{$\begin{array}{c}\text { Sample } \\
\text { point }\end{array}$} & 2041 & 3103 & 353 & 232 & 43 & Total \\
\hline NN & & 2165 & 2941 & 389 & 177 & 101 & sampl \\
\hline SVM & & 1956 & 3192 & 382 & 163 & 79 & $\begin{array}{c}\mathrm{e} \\
\text { points }\end{array}$ \\
\hline
\end{tabular}

Tab.6 Accuracy evaluation of three kinds of remote sensing classification of Yugu Dong

\begin{tabular}{|c|c|c|c|c|c|c|c|c|}
\hline Classification & Type & Forest & $\begin{array}{c}\text { Grassland/Shru } \\
\text { b }\end{array}$ & Farmland & $\begin{array}{c}\text { Architectur } \\
\mathrm{e}\end{array}$ & Water & Prod.Acc & Omission \\
\hline MLC & \multirow{3}{*}{ Forest } & 70.99 & 26.56 & 0.75 & 1.03 & 0.68 & 70.99 & 29.01 \\
\hline NN & & 74.06 & 22.21 & 1.07 & 0.33 & 2.32 & 74.06 & 25.94 \\
\hline SVM & & 69.34 & 27.85 & 0.83 & 0.31 & 1.67 & 69.34 & 30.66 \\
\hline MLC & \multirow{3}{*}{$\begin{array}{c}\text { Grassl } \\
\text { and/S } \\
\text { hrub }\end{array}$} & 14.00 & 83.31 & 1.20 & 1.05 & 0.45 & 83.31 & 16.69 \\
\hline NN & & 15.75 & 80.94 & 1.78 & 0.45 & 1.08 & 80.94 & 19.06 \\
\hline SVM & & 12.44 & 84.80 & 1.49 & 0.41 & 0.86 & 84.80 & 15.20 \\
\hline MLC & \multirow{3}{*}{$\begin{array}{c}\text { Farml } \\
\text { and }\end{array}$} & 1.33 & 14.13 & 77.07 & 7.47 & 0.00 & 77.07 & 22.93 \\
\hline NN & & 2.27 & 13.73 & 78.53 & 5.33 & 0.13 & 78.53 & 21.47 \\
\hline SVM & & 1.20 & 15.47 & 80.00 & 3.20 & 0.13 & 80.00 & 20.00 \\
\hline MLC & \multirow{3}{*}{$\begin{array}{l}\text { Archit } \\
\text { ecture }\end{array}$} & 4.02 & 8.91 & 5.75 & 81.32 & 0.00 & 81.32 & 18.68 \\
\hline NN & & 4.02 & 11.49 & 7.76 & 76.44 & 0.29 & 76.44 & 23.56 \\
\hline SVM & & 3.45 & 13.79 & 8.91 & 73.85 & 0.00 & 73.85 & 26.15 \\
\hline MLC & \multirow{3}{*}{ Water } & 7.41 & 1.85 & 5.56 & 31.48 & 53.70 & 53.70 & 46.30 \\
\hline $\mathrm{NN}$ & & 5.56 & 11.11 & 14.81 & 12.96 & 55.56 & 55.56 & 44.44 \\
\hline SVM & & 5.56 & 11.11 & 14.81 & 12.96 & 55.56 & 55.56 & 44.44 \\
\hline MLC & \multirow{3}{*}{$\begin{array}{c}\text { User. } \\
\text { Acc }\end{array}$} & 79.32 & 78.26 & 81.99 & 60.99 & 33.72 & \multirow{3}{*}{ OA } & 77.84 \\
\hline $\mathrm{NN}$ & & 78.01 & 80.24 & 75.80 & 75.14 & 14.93 & & 77.81 \\
\hline SVM & & 80.85 & 77.44 & 78.53 & 78.83 & 19.11 & & 77.92 \\
\hline MLC & Com & 20.68 & 21.74 & 18.01 & 39.01 & 66.28 & \multirow{3}{*}{ Kappa } & 0.62 \\
\hline $\mathrm{NN}$ & missio & 21.99 & 19.76 & 24.20 & 24.86 & 85.07 & & 0.62 \\
\hline SVM & $\mathrm{n}$ & 19.15 & 22.56 & 21.47 & 21.17 & 80.89 & & 0.62 \\
\hline
\end{tabular}

Note: Except for Kappa coefficient, all values in the table are percentages (\%)

Analysis of Table 6 shows that Yugu Dong uses three pixel-based classification methods to classify scenic resources with different accuracy. Among them, the overall accuracy of SVM classification is 77.92\%; the Kappa coefficient is 0.62, which is between 0.6-0.8. , Belongs to substantial. The classification results of 5 kinds of scenic resources are as follows:

ISSN: 0010-8189

(C) CONVERTER 2020

www.converter-magazine.info 
(1) Forest: Mainly misclassified into grassland/shrubland, architecture, and water. The main reason is that some forest is easily confused with grassland/shrubland. The final classification of forest is smaller than the actual area.

(2) Grassland/shrubland: Mainly misclassified into forest, farmland, architecture and water. The main reason is that some grassland/shrubland is mixed with forest, which is easy to be confused and misclassified. In the end, the classified area of grassland/shrubland is larger than actual.

(3) Farmland: It is mainly classified as grass/shrubland and architecture. The main reason is that the remote sensing data source was acquired during the dry season in April. The crops planted in the farmland in spring are similar in nature to grassland/shrubland, which is easy to be misclassified. In the end, the area of farmland classified using $\mathrm{NN}$ and SVM is larger than the actual area.

(4) Architecture: Mainly misclassified into grass/shrubland, farmland and forest. The main reason is that there are many scattered grass/shrubland, farmland and forest around the architecture, which are easy to be misclassified. The final use of MLC, NN architecture classification area is larger than actual.

(5) Water: It is mainly classified as architecture, forest, farmland, grassland/shrub. The main reason is that the surrounding architecture, forest, farmland, grassland/shrubland and water are easily confused. The shadows of the hills have also been mistakenly divided into water. In the end, the classified area of water is larger than the actual area.

\section{Discussion}

Using three pixel-based classification methods, the overall accuracy of GF-2 image classification for three different geomorphic units is in the range of $74.97 \%-79.21 \%$, the Kappa coefficient is between $0.57-0.65$, and the classification effect is good. From the perspective of classification speed of the three classification methods, MLC $>$ SVM $>$ NN, MLC classification speed is faster than SVM and NN.

\subsection{Comparison of classification methods of Baili Xia}

The scenic area uses MLC, NN, and SVM to meet the classification accuracy requirements. Compared the three methods, MLC has higher classification accuracy for forest and architecture, which are $73.91 \%$ and $85.25 \%$ respectively, while for grass/shrubland, farmland, and water. The accuracy is relatively low, 87.31\%, 59.54\%, $76.11 \%$; NN has a higher classification accuracy for grassland/shrubland, $91.28 \%$, and a relatively low classification accuracy for forest, 66.82\%; SVM has high classification accuracy for farmland and water, $63.07 \%$ and $80.57 \%$ respectively, and relatively low classification accuracy for buildings, $64.75 \%$ respectively. The overall accuracy of classification: MLC (79.21\%)>SVM (78.19\%)>NN (77.54\%). In summary, the overall accuracy of MLC classification in the erosional Zhanggu landform unit is $79.21 \%$, and the Kappa coefficient is 0.65 , which is higher than SVM and NN, which can better reflect the actual situation of the scenic area, while NN is lower, with an overall accuracy of $77.54 \%$, Kappa coefficient is 0.62 .

\subsection{Comparison of classification methods of Longmen Tianguan}

The scenic area uses MLC, NN and SVM three methods to meet the classification accuracy requirements. Comparing the three methods, MLC has higher classification accuracy for grassland/shrubland, farmland, and architecture, respectively, $94.53 \%, 67.68 \%$, and $85.22 \%$, while classification accuracy for water is relatively low, only 54.17\%; NN has higher classification accuracy for forest, The classification accuracy of farmland is relatively high, $64.93 \%$ and $67.68 \%$, respectively. The classification accuracy of grassland/shrubland is relatively low, which is $90.22 \%$; SVM has a high classification accuracy for waters, $62.50 \%$, and a relatively low classification accuracy for woodland, farmland and buildings, 52.60\%, 64.97\%, and $80.87 \%$ respectively. The overall accuracy of

ISSN: 0010-8189 
classification: $\mathrm{NN}(78.66 \%)>\mathrm{MLC}(76.99 \%)>\mathrm{SVM}(74.97 \%)$. In summary, the overall accuracy of $\mathrm{NN}$ classification in the granite fault structure canyon geomorphology unit is $78.66 \%$, and the Kappa coefficient is 0.62 , which is higher than MLC and SVM, which can better reflect the actual situation of the scenic area, while the SVM is lower, with an overall accuracy of $74.97 \%$., Kappa coefficient is 0.57 .

\subsection{Comparison of classification methods of Yugu Dong}

The scenic area uses MLC, NN and SVM three methods to meet the classification accuracy requirements. Comparing the three methods, MLC has a higher classification accuracy of $81.32 \%$ for architecture, while classification accuracy for farmland and water areas is relatively low, $77.07 \%$ and $53.70 \%$ respectively; $\mathrm{NN}$ has higher classification accuracy for forests and water, respectively, 74.06. \%, 55.56\%, the classification accuracy for grassland/shrubland is relatively low, $80.94 \%$; SVM classification accuracy for grassland/shrubland, farmland and water is relatively high, respectively, $84.80 \%, 80.00 \%, 55.56 \%$, for forest, architecture The classification accuracy is relatively low, $69.34 \%$ and $73.85 \%$ respectively. Overall classification accuracy: SVM (77.92\%)>MLC $(77.84 \%)>\mathrm{NN}(77.81 \%)$. In summary, the overall accuracy of SVM classification in the karst cave spring geomorphology unit is $77.92 \%$, and the Kappa coefficient is 0.62 , which is higher than MLC and NN, which can better reflect the actual situation of the scenic area. $\mathrm{NN}$ is lower, with an overall accuracy of $77.81 \%$. Kappa The coefficient is 0.62 .

\section{Conclusions}

In the research, it was found that based on GF-2 images, using RS and GIS technology to identify scenic resources, compared with traditional visual observation, it is less affected by terrain, traffic, weather and other conditions, and the identification range is wider, which can be used to identify scenic resources in national park. Carry out comprehensive identification, especially the GF-2 image has the advantages of rich information, high definition, intuitive image, strong real-time, fast image formation, fast data acquisition, which greatly reduces the investigation and identification of scenic resources. It has obvious advantages in resource space identification. However, because the pixel-based classification is mainly based on statistical principles to statistically classify the spectral characteristics of the image, the scenic resource with small spectral characteristics in the remote sensing image will be classified into one category when the scenic resource is classified, which will affect the spectrum. The classification accuracy of forest, grassland/shrubland and farmland with similar characteristics. In addition, due to the presence of mountain shadows, the spectral characteristics of the shadows are similar to those of the water. In actual classification, it is possible to classify the pixels in the shadows and the water into the same category. Therefore, pixel-based classification is suitable for rapid identification of scenic resources in remote sensing images, combined with other data to determine field survey routes and key survey areas in GIS, and detailed identification through field survey data combined with visual interpretation, which is beneficial to scenery Digitization and systematization of resource identification. According to the research, Baili Xia in Yesanpo uses MLC, Longmen Tianguan uses NN, and Yugu Dong uses SVM with the highest overall accuracy.

The application of GF-2 images in national park has very broad prospects, especially for the study of digital planning and management of national park, which has important practical significance. The types of national park are more complex, and the higher the accuracy of identification and classification, the higher the accuracy of identification and classification. The greater the practical guiding significance of national park planning and management, can also promote the sustainable development of local tourism, it is necessary to further study the classification system of scenic resources and the classification algorithm of GF-2 images (such as object-oriented classification, etc.).

\section{References}

ISSN: 0010-8189 
[1] Z. Chen, "Research on high-resolution remote sensing image classification technology," Beijing: Chinese Academy of Sciences, 2006.

[2] Y. Zhou, "Research on object-oriented high-resolution remote sensing image classification technology," China University of Geosciences (Beijing), 2015.

[3] C. Jiao, "The impact of returning farmland to forests on the land use and ecological service value of Tianmu Lake scenic area," Yangzhou University, 2018.

[4] H. Li, H. Wu, M. Xue, et al., "Improvement of maximum likelihood classification for land inspectors of confusing ground objects," Remote Sensing Information, vol. 33, no. 06, pp. 132-138, 2018.

[5] C. Huang, L. S. Davis, J. R. G, "Townshend, an assessment of support vector machines for land cover classification,” International Journal of Remote Sensing, vol. 23, no. 4, 2002.

[6] C. J. Li, H. He, W. Li, "Research on the cultivated land extraction technology of agricultural remote sensing images based on support vector machine," Instrument Technology, no. 11, pp. 5-8+48, 2018.

[7] J. D. Paola, R. A. Schowengerdt, "A review and analysis of back propagation neural networks classification of remotely-sensed multi-spectral imager," International Journal Remote sensing, vol. 16, no. 16, pp. 3033-3058, 1995.

[8] Y. Q. Yang, "Comparative study of remote sensing image classification methods under different geomorphological units," Shanxi Normal University, 2016.

[9] Y. Pan, J. H. Yang, W. B. Wu, "Application of neural network remote sensing classification based on rough set reduction,” Remote Sensing Information, vol. 27, no. 04, pp. 86-90+74, 2012.

[10] P. Ghimire, D. Lei, N. Juan, "Effect of image fusion on vegetation index quality - a comparative study from gaofen-1, gaofen-2, gaofen-4, landsat-8 OLI and MODIS imagery," Remote Sensing, doi:10.3390/rs12101550, vol. 12, no. 10, pp. 1550, 2020.

[11] Z. Y. Z, B. Si, Y. Lin, et al., "Mapping and discriminating rural settlements using gaofen-2 images and a fully convolutional network," Sensors, vol. 20, no. 6062, 2020.

[12] H. Karunarathna, P. Maduwantha, B. Kamranzad, et al., "Evaluation of spatio-temporal variability of ocean wave power resource around Sri Lanka,” Energy, doi: 10.1016/j. energy, pp.117503, 2020.

[13] J. X. Huang, Y. Z. Hou, W. Su, etc., "Extraction method of corn and soybean planting area based on GF-1 WFV data," Journal of Agricultural Engineering, vol. 33, no. 7, pp. 164-170, 2017.

[14] X. G. Xu, Q. Z. Li, W. C. Zhou, et al., "Application of high-resolution remote sensing images to extract crop planting area," Remote Sensing Technology and Application, vol. 23, no.1, pp. 17-23, 2008.

[15] M. A. Cochrane, "Using vegetation reflectance variability for species level classification of hyperspectral data," International Journal of Remote Sensing, vol. 21, no. 10, pp.2075-2087, 2000.

[16] A. P. Yunus, J. Dou, N. Sravanthi, "Remote sensing of chlorophyll-a as a measure of red tide in Tokyo Bay using hotspot analysis," Remote Sens, Appl, Soc, Environ, vol. 2, pp. 11- 25, 2015.

[17] H. K. Lotze, "Depletion, degradation, and recovery potential of estuaries and coastal seas," Science 2005, vol. 312, pp. 1806-1809.

[18] M. Rani, M. Masroor, P. Kumar, "Remote sensing of ocean and coastal environment-overview," Remote Sens, Ocean Coast, Environ, pp. 1-15, 2021.

[19] Y. Luo, "Sustainability associated coastal eco-environmental problems and coastal science development in China," Bull, Chin, Acad, Sci, vol. 31, pp. 1133-1142, 2016.

[20] E. Zohdi, M. Abbaspour, "Harmful algal blooms (red tide): A review of causes, impacts and approaches to monitoring and prediction,” Int. J. Environ. Sci. Technol. vol. 16, pp. 1789-1806, 2019.

[21] G. Yang, M. Tian, X. Zhang, et al., "Quartz sandstone peak forest landforms of Zhangjiajie Geopark, northwest Hunan Province, China: pattern, constraints and comparison," Environmental Earth Sciences, vol. 65, no. 6, pp.1877-1894, 2012.

[22] M. Sun, Y. Deng, M. Li, et al., "Extraction and analysis of blue steel roofs information based on CNN using gaofen-2 imageries," Sensors, vol. 20, no. 16, pp. 4655, 2020.

[23] H. Huang, Q. Li, Y. Zhang, "Urban residential land suitability analysis combining remote sensing and social sensing data: a case study in Beijing, China,” Sustainability, pp. 11, 2019.

ISSN: 0010-8189

www.converter-magazine.info 
Volume 2021, No. 4

[24] J. Yang, Y. Liu, S. Wang, "An overview of the methods of GIS-based land-use suitability analysis," Proc. SPIE 2007, vol. 6754, pp. 675438.

[25] J. Malczewski, "GIS-based land-use suitability analysis: A critical overview. Prog. Plan,” vol. 62, pp. 3-65, 2004.

[26] S. K. Misra, S. Sharma, "Site suitability analysis for urban development: a review," Int. J. Recent Innov. Trends Comput. Commun, vol. 3, pp. 3647-3651, 2015.

[27] J. Li, J. A. Benediktsson, B. Zhang, et al., "Spatial technology and social media in remote sensing: a survey," Proc, IEEE 2017, pp, 1-10.

[28] J. J. Hu, "Research on object-oriented land use information extraction based on GF-2 images," Chengdu University of Technology, 2017.

[29] W. Wang, J. Li, X. Y. Chen, et al., "Remote sensing recognition of taro in northern Guangdong based on Gaofen-2 satellite image," Guangdong Agricultural Sciences, vol. 47, no. 06, pp. 126-133, 2020.

[30] F. F. Li, "Structural analysis of the landscape of Yesanpo National Geopark," China University of Geosciences (Beijing), 2007.

[31] Yesanpo Tourism Net. Overview of Yesanpo Structure http://www.hbysp.cn/guide/geology, no. 1, 2018.

[32] H. Li, H. Wu, M. Xue, et al., "Improvement of maximum likelihood classification for land inspectors of confusing ground objects," Remote Sensing Information, vol. 33, no. 06, pp. 132-138, 2018.

[33] K. P. Li, "Research on the recognition method of corn rust based on hyperspectral imaging technology," Henan Agricultural University, 2017.

[34] W. Q. Huang, "Analysis of urban forest park landscape changes based on high-resolution images," Nanjing Forestry University, 2014.

ISSN: 0010-8189 